\title{
Disciplined doctors: learning from the pain of the past
}

\section{Jessica J Liu, ${ }^{1}$ Chaim M Bell ${ }^{2}$}

${ }^{1}$ University Health Network, University of Toronto, Department of Medicine, Toronto, Canada ${ }^{2}$ Mount Sinai Hospital, University of Toronto, Department of Medicine, Toronto, Canada

\section{Correspondence to}

Dr Jessica J Liu, 200 Elizabeth Street, 14EN213, Toronto M5G 2C4, Canada; jessica.liu@uhn.ca

Accepted 14 April 2016 Published Online First 4 May 2016

\section{CLLinked}

- http://dx.doi.org/10.1136/ bmjqs-2015-004974

\section{CrossMark}

To cite: Liu JJ, Bell CM. BMJ Qual Saf 2017;26:174-176.
The discipline of physicians is an issue of public trust. In the majority of Western countries, physician misconduct is selfgoverned at a state-wide or provincial level by physician licensing and regulatory associations. In the USA, this responsibility falls under the jurisdiction of state medical licensing boards. These state boards review complaints against physicians and investigate whether standards of care and professionalism have been upheld; they also decide upon specific punishments for misconduct, including fines, extra training and education, and licence suspension and revocation. However, there is no overarching federal standard with which each state regulatory board must comply, nor is there a unifying body that compares individual states and their quality standards and policies for physician disciplinary proceedings.

In this issue, Harris and Byhoff ${ }^{1}$ investigate physician misconduct cases using a US database of medical board disciplinary actions from 2010 to 2014. The authors report up to a fourfold variation in the annual rate of physician disciplinary actions between state medical boards. They also suggest potential explanations for such variability, such as variations in patient factors, physician factors and significant differences in the processes related to disciplinary proceedings by the individual medical boards. Ultimately, the authors recommend policies to improve standardisation and provide more consistent regulation to physicians in the name of public safety. Their findings underscore the timely issue of using physician discipline and misconduct as an extreme marker of physician quality. Importantly, it is among the first to highlight such variability across jurisdictions.

Historically, investigations on physician misconduct have limited their focus to a state-wide or provincial level, or have centred on malpractice claims and lawsuits against physicians. ${ }^{2-9}$ Only a handful of studies have examined issues of physician misconduct on a national level. ${ }^{10-16}$ Physician disciplinary proceedings arise in response to a broad range of issues; these include addictive behaviours, inappropriate prescribing, poor record keeping, fraudulent billing, sexual impropriety and gross incompetence. ${ }^{15}$ In addition, medical regulatory boards make decisions on resultant penalties for misconduct that are tailored to the specific offense, such as: licence revocation, suspension or restriction, mandated retraining, psychological counselling and/or rehabilitation, formal reprimand, and fine or cost repayment. ${ }^{67}{ }^{11}$ Moreover, patient complaints data suggest that a small proportion of physicians typically receive the majority of complaints, that is, they are 'frequent flyers'. ${ }^{17}$ Similar results have been shown with disciplinary proceedings-over $10 \%$ of disciplined physicians are reoffenders. ${ }^{11}$ Understanding more about physician misconduct and disciplinary actions can provide valuable insight into poor physician quality. In addition, there may be potential for using these data in order to identify 'at-risk' physicians and target potential interventions.

The vast majority of physicians practice medicine without any misconduct-internationally, estimated disciplinary rates range from $0.3 \%$ to $2.8 \%$ of all practising physicians. ${ }^{2}$ 6-7 While rates appear reassuringly low, they likely underestimate actual rates of misconduct. Not all misconduct generates a complaint (from patients or colleagues). Moreover, some physicians may voluntarily relinquish their licences prior to any formal disciplinary action. But, faced with the results highlighted by Harris and Byhoff, we must ask how physician disciplinary rates could vary so considerably between jurisdictions.

Harris and Byhoff hypothesise that a variety of factors, including physician characteristics, patient expectations and 
medical regulatory board characteristics, contribute to the observed variable disciplinary rates. In turn, these may relate to male gender, lack of board certification, older age and certain specialties including family practice and psychiatry. ${ }^{6} 11$ As well, sociocultural differences of physicians and patients across jurisdictions may lead to variable expectations of healthcare. This is similar to a well-described marketing phenomenon known as geographic segmentation, in which consumers have variable expectations depending on the region in which they live, driven by a variety of sociocultural reasons. Such factors may differentially drive patient complaints to physician regulatory colleges between regions. While Harris and Byhoff are the first to note such variation between jurisdictions and disciplinary proceedings, the notion that aspects of healthcare organisation and delivery vary widely between jurisdictions is hardly new. For several decades, the Dartmouth Atlas Project has described the significant variation in the provision, distribution and utilisation of healthcare resources in the USA. ${ }^{18}$ Ultimately, some of this variation may be warranted, in part, due to the complex interplay between jurisdiction-specific patient and physician factors mentioned earlier. However, there is certainly support for increased jurisdictional standardisation between states in many aspects of healthcare, and one potentially modifiable target is the state regulatory bodies' disciplinary process.

In their article, Harris and Byhoff highlight that disciplinary rate variation may also be related to differing structures, organisation and methodologies implemented by state regulatory bodies, as well as to state-by-state variations in the disciplinary proceedings process itself. We agree with the authors that it is here that important improvements can be implemented.

Interestingly, most physician misconduct is initially identified through patient complaints, rather than, for example, by physician colleagues. ${ }^{6}$ And surprisingly, in many cases, the likelihood of a complaint to medical regulatory boards often relates to poor communication related to the incident, rather than the severity of the incident itself. ${ }^{8}$ Viewed this way, at least for certain types of unprofessional behaviours, complaints data gathered by state medical boards in the disciplinary investigation process may provide a better understanding of what patients value in their interactions with their physicians. These data may provide unique information on physician quality assessment, as opposed to other methods such as peer assessment or board certification exams. The problem, however, is that this construct of physician disciplinary proceedings as a reflection of patient dissatisfaction (whether due to poor physician communication or other reasons) does not apply uniformly to all cases of physician discipline. Patient complaints and disciplinary action are not interchangeable-not all complaints are escalated to warrant disciplinary action. Complaints against physicians are temporally more proximal than disciplinary findings, which are, in turn, distal to the initial inciting event of poor, inappropriate or substandard quality of care. It may be that patient dissatisfaction drives complaints to regulatory boards and subsequent disciplinary action only when considering less-severe episodes of unprofessionalism, that is, those that do not ultimately warrant escalation to disciplinary action and punishment. Thus, the concept of physician disciplinary proceedings as a reflection of the patient experience is controversial, and although not uniformly applicable, a novel consideration when studying this population of physicians.

In general, the authors report that descriptions of specific disciplinary cases were not consistently captured in sufficient detail, regardless of individual state medical board. Surprisingly, for over half of all 26804 cases, no details whatsoever were provided about the disciplinary finding or action. Moreover, the authors did not observe an association between the rate of minor and major disciplinary actions; hence, they suggest that it was not a case of certain boards being more lenient, but between-state variation in categorising minor versus major actions. Certainly, however, variations in jurisdictional leniency have been seen; after losing their licence to practice in one state, physicians have been granted permission to practice in others, although with restricted practices. ${ }^{19} 20$ Nonetheless, this variation in the disciplinary process and leniency in the face of documented misconduct highlight the need for more complete methodologies for categorising details and severity of misconduct, as well as standardising punishment for episodes of misconduct in order to help contextualise disciplinary actions between states.

What can individual state medical boards do about this variability in disciplinary proceedings? Standardisation of data collection and categorisation of disciplinary findings are an essential first step in any process that will help states benchmark against others. Better yet, this type of coordinated effort may come from a federal level or through improved cooperation between states. Without these efforts, it will be difficult to separate any addressable signal from the inherent noise. This would help state medical boards delineate whether differences in observed disciplinary rates relate to the structure and methodology of the organisation, or to patient or physician differences. This could, in turn, inform possible programme improvements in the disciplinary proceedings process or aid in the design of intervention strategies targeted towards at-risk physicians. Either way, more and better data can only improve the decision-making. Ultimately, regardless of where one lives, the pain of the past in one state should improve the care of all patients in the future. 
Competing interests None declared.

Provenance and peer review Commissioned; internally peer reviewed.

\section{REFERENCES}

1 Harris JA, Byhoff E. Variations by state in physician disciplinary actions by US medical licensure boards. BMJ Qual Saf 2017;26:200-8.

2 Morrison J, Wickersham P. Physicians disciplined by a state medical board. JAMA 1998;279:1889-93.

3 Cardarelli R, Licciardone JC, Ramirez G. Predicting risk fordisciplinary action by a state medical board. Tex Med 2004;100:84-90.

4 Cardarelli R, Licciardone JC. Factors associated with highseverity disciplinary action by a state medical board: a Texas study of medical license revocation. J Am Osteopath Assoc 2006;106:153-6.

5 Clay SW, Conatser RR. Characteristics of physicians disciplined by the State Medical Board of Ohio. J Am Osteopath Assoc 2003;103:81-8.

6 Khaliq AA, Dimassi H, Huang CY, et al. Disci- plinary action against physicians: who is likely to get disciplined? Am J Med 2005;118:773-7.

7 Kohatsu ND, Gould D, Ross LK, et al. Characteristics associated with physician discipline: a case-control study. Arch Intern Med 2004;164:653-8.

8 Hickson GB, Federspiel CF, Pichert JW, et al. Patient complaints and Malpractice Risk. JAMA 2002;287:2951-7.

9 Stelfox HT, Gandhi TK, Orav EJ, et al. The relation of patient satisfaction with complaints against physicians and malpractice lawsuits. Am J Med 2005;118:1126-33.
10 Elkin KJ, Spittal MJ, Elkin DJ, et al. Doctors disciplined for professional misconduct in Australia and New Zealand, 20002009. Med J Austral 2009;194:452-6.

11 Alam A, Klemensberg J, Griesman J, et al. The characteristics of physicians disciplined by professional colleges in Canada. Open Med 2011;5:166-72.

12 Alam A, Kuryak P, Klemensberg J, et al. The characteristics of psychiatrists disciplined by professional colleges in Canada. PLOS ONE 2012;7:e50558.

13 Alam AQ, Khan J, Liu J, et al. Characteristics and rates of disciplinary findings amongst anesthesiologists by professional colleges in Canada. Can J Anesth 2013;60:1013-19.

14 Liu JJ, Alam AQ, Goldberg HR, et al. Characteristics of internal medicine physicians disciplined by professional colleges in Canada. Medicine (Baltimore) 2015;94:e937.

15 Elkin K, Spittal MJ, Elkin D, et al. Removal of doctors from practice for professional misconduct in Australia and New Zealand. BMJ Qual Saf 2012;21:1027-33.

16 State Medical Boards' Disciplinary Actions. Secondary State Medical Boards' Disciplinary Actions. Public Citizen website. http://www.citizen.org/statemedicalboardsdisciplinaryactions

17 Spittal MJ, Bismark MM, Studdert DM. The PRONE score: an algorithm for predicting doctors' risks of formal patient complaints using routinely collected administrative data. BMJ Qual Saf 2015;24:360-8.

18 http://www.dartmouthatlas.org/ (accessed 6 Apr 2016).

19 Skolnick AA. Prison deaths spotlight how boards handle impaired, disciplined physicians. JAMA 1998;280:1387-90.

20 Skolnick AA. Critics denounce staffing jails and prisons with physicians convicted of misconduct. JAMA 1998;280: 1391-2. 